\title{
BIOSSEGURANÇA EM REBANHOS LEITEIROS NA AGRICULTURA FAMILIAR - SUDOESTE PARANAENSE
}

\author{
Ana Paula Sachet ${ }^{1}$, Camila Paula Baron ${ }^{1}$, Carina Franciscato ${ }^{1}$, Adolfo Firmino Silva- \\ Neto ${ }^{1}$ \\ 1 UFFS \\ Correspondência: Carina Franciscato: carinafranciscato@uffs.edu.br
}

\begin{abstract}
RESUMO: Fundamentado na importância que a produção de leite tem para a agricultura familiar do sudoeste do Paraná, foi realizada uma pesquisa sobre a biossegurança em rebanhos leiteiros na agricultura familiar da região, que consistiu em um levantamento do conhecimento dos agricultores familiares sobre as práticas básicas de biossegurança adotadas. A estratégia para 0 desenvolvimento da pesquisa foi a aplicação de questionários pertinentes ao tema supracitado, com visitas in locu, para obter o conhecimento da realidade das propriedades e aquisição dos dados referentes à pesquisa. Observou-se um comprometimento da biossegurança nas propriedades pesquisadas, pois apesar de todas afirmarem vacinar os animais, $89 \%$ realizarem o combate de roedores e $81 \%$ fornecerem colostro para os bezerros, $36 \%$ fornecem leite de vacas com mastite e $61 \%$ leite com resíduo de antibiótico; $36 \%$ das propriedades realizavam reposição do rebanho com animais externos, mas somente uma realizava exame na aquisição destes; em $24 \%$ das propriedades existia o trânsito de animais sem controle; $64 \%$ das propriedades utilizava inseminação artificial, enquanto $36 \%$ utilizava apenas monta natural como método reprodutivo; $85 \%$ não realizava quarentena; $56 \%$ não fazia exames laboratoriais; $48 \%$ não contavam com auxílio de médico veterinário ou técnico; $53 \%$ não adota calendário de vermifugação, mas todas realizam o controle de ectoparasitas; em $88 \%$ não existe o controle de qualidade da água; apenas $28 \%$ utilizam luvas no parto; os materiais perfurocortantes não são descartados adequadamente na maioria das propriedades; $67 \%$ destas não fazem o isolamento dos animais; em $28 \%$ não existia um destino sanitário adequado às carcaças de animais mortos. Com base nos resultados obtidos, pode-se concluir que grande parte dos produtores de leite da agricultura familiar do município de Realeza-PR desconhece a maioria das práticas de biossegurança que devem ser aplicada ao rebanho leiteiro.
\end{abstract}

Palavras-chave: agricultura familiar; biossegurança; bovinocultura de leite

\section{BIOSAFETY IN DAIRY HERDS ON FAMILY FARMING - SOUTHWEST OF THE STATE OF PARANÁ}

\begin{abstract}
Based on the importance of milk production has for family farming of southwest of the "Paraná" state, a survey was conducted on biosafety in dairy herds on family farming in the region. This study consisted in a survey of knowledge of the family farming about the biosafety practices adopted in the properties. The research consisted in application of a questionnaire, made in locus for knowledge about the reality on the farms and to obtain the information about the research. The biosafety is impaired in surveyed properties, because despite all to do vaccinate in the animals, $89 \%$ combat rodents and $81 \%$ supply colostrum to calves, $36 \%$ provide mastitic milk and $61 \%$ milk from cows treated with antibiotics; $36 \%$ of the properties makes cattle replacement with outside animals, but only one performed blood test in the acquisition of these; in $24 \%$ of the properties there is not control in animals transit; $64 \%$ of the properties used artificial insemination, while $36 \%$ used only natural mating as reproductive method; $85 \%$ did not quarantine; $56 \%$ did not laboratory tests periodically; $48 \%$ did not have veterinarian or technician; did not worming schedule; but all performed the control of ectoparasites; in $88 \%$ there is not control of water quality; only $28 \%$ used gloves at birth; the cutting materials are not properly discarted in the most properties; $67 \%$ of these did not the isolation of animals; in $28 \%$ of the properties there was not an adequately sanitary destination of the carcasses of dead animals. The results this study showed that the many milk producers of family farming do not know the most of biosafety practices that should be applied to the dairy cattle.
\end{abstract}

Key Words: family farming; biosafety; dairy cattle 


\section{INTRODUÇÃO}

Nas duas últimas décadas 0 Sudoeste do Paraná aumentou significativamente a sua produção de leite, passando de 163.727 litros de leite produzidos em 1996 (Nunes, 2008) para 956.341 litros em 2010 (Mezzadri, 2012). A origem de tal fenômeno está na implementação de políticas públicas de âmbito federal e regional que visavam o fortalecimento da Agricultura Familiar, a qual encontrou na atividade leiteira a garantia de uma renda mensal (Casari e Tormem, 2007).

Contudo, a região vem enfrentando problemas sérios com relação à qualidade do leite. Nos últimos anos, muitas propriedades produziram leite com elevada contagem bacteriana total (CBT) (Hoogerheide e Mattioda, 2012). O mesmo ocorrendo com relação a contagem de células somáticas (CCS) (Mattioda et al., 2011). Ou seja, a qualidade do leite da região está fora dos parâmetros preconizados pela legislação especifica, a Instrução Normativa no 62/2011 do Ministério da Agricultura Pecuária e Abastecimento MAPA (Brasil, 2011), assim como ocorre em outras regiões do país (Oliveira et al., 2012). Na origem deste problema está presente a questão sanitária dos rebanhos, a qual, por sua vez, é dependente da realização de um conjunto de práticas voltadas para a prevenção das doenças do gado leiteiro.

No sudoeste paranaense a produção leiteira é sustentada, principalmente, por agricultores familiares que se vincularam à atividade há menos de quinze anos. Neste sentido, é uma bacia leiteira relativamente jovem, onde a mão de obra, predominantemente familiar, ainda se encontra em processo de qualificação para a atividade (IPARDES, 2009).

Pesquisas têm demonstrado que programas regionais de assistência a produtores de leite são fundamentais para a produção de leite de qualidade (Nero et al., 2005). Na região estudada, cursos técnicos de curta duração são oferecidos aos agricultores familiares pelo poder público municipal e por setores organizados da sociedade, especialmente sindicatos e cooperativas. Entretanto, os dados sobre a qualidade microbiológica do leite parecem indicar falhas no processo de formação destes agricultores para a atividade leiteira, ou a existência de fatores que interferem na adoção de práticas profiláticas no rebanho.

A partir disso, o objetivo do estudo foi avaliar o conhecimento a respeito de medidas preventivas de doenças do gado leiteiro e a percepção sobre aspectos sanitários do rebanho entre produtores familiares do município de Realeza, Paraná.

\section{MATERIAL E MÉTODOS}

Segundo dados da Secretaria Municipal da Agricultura, o município de Realeza possui 634 produtores de leite. Dentro deste universo amostral foram selecionados aqueles que atendiam aos critérios previamente fixados no projeto para caracterização como produtor de leite da agricultura familiar: propriedades com área compreendida entre 20 e 50 hectares; produção de leite não ser a única atividade agrícola da propriedade; um rebanho com no máximo 20 vacas em lactação; pelo menos três membros da família residirem na propriedade, e ter no mínimo dois anos de atuação na atividade.

Com a aplicação deste critério de exclusão chegou-se ao número de 126 produtores. Após a análise das informações fornecidas pela cooperativa e pelo laticínio do município, verificou-se que os produtores estavam distribuídos, de maneira não homogênea, por oito comunidades rurais da seguinte forma: Linha Vitória, 6; Linha Santa Terezinha, 
15; Linha Saltinho 42; Linha Progresso, 7; Linha São Miguel 5; Linha Capanema 4; Linha Sétimo, 4; e Linha Maravilha, 17.

Na primeira etapa do trabalho de campo uma equipe de quatro pesquisadores visitou as comunidades com o objetivo de convidar os produtores a participarem da pesquisa e simultaneamente realizar a confirmação do endereço dos produtores selecionados. Neste momento descobriu-se que alguns produtores tinham abandonado a atividade, o que reduziu o número de observações para 100 produtores.

Todos os produtores contatados na etapa de convite para a pesquisa aceitaram participar e assinaram 0 Termo de Consentimento livre esclarecido. A aplicação do questionário propriamente dito ocorria em finais de semana, no início da tarde, com o objetivo de minimizar o impacto sobre a rotina de trabalho das famílias participantes, especialmente sobre a ordenha.

A aplicação do questionário foi feita por uma equipe de 15 alunos de graduação do Curso de Medicina Veterinária da Universidade Federal da Fronteira Sul. Os alunos receberam treinamento por dois meses, antes do início da aplicação do questionário nas comunidades rurais de Realeza. No período de férias os discentes aplicaram os questionários em suas cidades de origem, localizadas no Oeste Catarinense, como uma etapa piloto. A aplicação dos questionários foi feita em dupla e todas elas explicavam o significado das perguntas para os produtores. Como ação padrão, este cuidado foi tomado com o intuito de uniformizar o procedimento de coleta de dados. Outra medida tomada para evitar a ocorrência de respostas tendenciosas, foi a aplicação de todos os questionários em cada comunidade no mesmo dia.
Para garantir a confiabilidade dos questionários, alguns temas foram avaliados por mais de uma pergunta. E com o cruzamento das informações, foi possível avaliar se efetivamente a primeira informação era confiável, ou não.

Os resultados obtidos foram armazenados em mídia digital e os questionários respondidos foram arquivados na sala do grupo de pesquisa localizada no campus de Realeza da Universidade Federal da Fronteira Sul - UFFS.

Os resultados foram transformados em dados numéricos, com base no número de opção repetida para cada pergunta dos questionários, assim estes foram tabulados em planilha eletrônica, analisados e relacionados com informações de sanidade do rebanho obtidas a partir do questionário.

O questionário aplicado nesta pesquisa consistiu de perguntas sobre as práticas básicas de biossegurança adotadas pelos produtores. As informações obtidas da aplicação dos questionários foram analisadas dividindo-se os temas em doze assuntos relativos a sanidade: forma de aquisição de animais, realização de quarentena, forma de realização de vacinação, uso da água, manejo de resíduos, uso de antiparasitários, cuidado no trânsito de animais, e práticas gerais de biossegurança envolvendo fornecimento de colostro, de medicamentos e cuidados de higiene dos alimentos fornecidos aos animais. Para não induzir as respostas foi construída uma sequência aleatória das perguntas. De posse dos questionários respondidos, os temas gerais foram distribuídos em 49 itens a serem analisados: fonte de aquisição do rebanho, presença de assistência técnica, periodicidade da assistência técnica, origem da assistência técnica, exame dos animais na aquisição, responsável pelo exame 
dos animais antes da aquisição, prática de realização de exames laboratoriais, tipos de exames realizados, conhecimento sobre a procedência dos animais, conhecimento sobre o que é quarentena, realização de quarentena, realização de vacinação dos animais, para quais doenças são vacinados, noção sobre o que é calendário vacinal e adoção de calendário vacinal na propriedade, origem da água fornecida aos animais, existência de monitoramento da água fornecida, destino da carcaça dos animais que morrem, cuidados dos produtores com a própria segurança na condução de fetos abortados, noção sobre calendário de vermifugação, periodicidade das vermifugações, controle de ectoparasita, periodicidade de controle de ectoparasitas, formas de controle de ectoparasitas, realização de exames, periodicidade da realização dos exames, destino das vacas doentes, serviços laboratoriais utilizados, prática de envio de amostras para laboratório, controle de saída e entrada de animais, tipo de manejo reprodutivo no rebanho, uso de medicamentos, verificação do prazo de validade do medicamento, aspecto do medicamento a ser utilizado, destino do material perfuro-cortante, monitoramento da ingestão do colostro, realização de um banco de colostro, armazenamento das rações, contaminação da água e alimentos com fezes e urina, controle de roedores, controle de moscas, local apropriado para o parto dos animais, discriminação do local de parto, cuidados com a criação de bezerras, qual destino das vacas, destino do leite de vacas com mastite, destino do leite de vacas tratados com antibióticos, faz a terapia da vaca seca, existe local próprio para as vacas secas.

\section{RESULTADOS}

Com relação a reposição de animais no rebanho, trinta e seis por cento das propriedades pesquisadas fazem a reposição de animais com a incorporação de indivíduos externos ao rebanho. Sendo que este grupo se subdividiu em propriedades que só fazem a reposição com animais externos, e propriedades que fazem a reposição com animais externos combinada com a incorporação de animais nascidos no próprio rebanho, conforme dados apresentados na tabela 1. Por outro lado, sessenta e quatro por cento das propriedades realizam reposição do rebanho somente com animais nascidos nas mesmas.

\begin{tabular}{|c|c|c|}
\hline Fontes de reposição do rebanho & $\mathrm{N}^{\circ}$ de Propriedades & $\%$ \\
\hline Reposição exclusivamente externa & 13 & 13 \\
\hline Reposição exclusivamente interna & 64 & 64 \\
\hline Reposição intema com compra de vacas & 10 & 10 \\
\hline Reposição intema com compra de novilhas & 7 & 7 \\
\hline $\begin{array}{l}\text { Reposição interna com compra de vacas e } \\
\text { novilhas }\end{array}$ & 6 & 6 \\
\hline Total & 100 & 100 \\
\hline
\end{tabular}

Quanto ao trânsito de animais nas propriedades, vinte e quatro por cento dos produtores afirmaram que existia trânsito de animais entre propriedades próximas e dentre esses, vinte por cento declararam ser devido ao empréstimo de touros. Além disso, sessenta e quatro por cento das propriedades utilizava inseminação artificial, enquanto trinta e seis por cento utilizava apenas monta natural como método reprodutivo.

Das cem propriedades pesquisadas em oitenta e nove se desconhecia a realização de quarentena. $E$ entre todas as propriedades investigadas apenas uma realizava exames na aquisição dos animais.

Quanto a realização periódica de exames, em sessenta e cinco por cento 
das propriedades entrevistadas não se praticava esta rotina. Nos outros trinta e cinco por cento, vinte propriedades já realizaram exames para brucelose, dez para tuberculose, quatro para verminoses, uma para carbúnculo e apenas três propriedades fizeram exames microbiológicos para isolamento de agentes etiológicos da mastite. Destas propriedades, apenas oito declararam realizar exames periódicos. Contudo, quando os produtores foram inqueridos sobre o período de tempo para a realização dos mesmos, seis declararam realizar anualmente.

Quanto à utilização de assistência técnica nas propriedades, quarenta e oito delas não contam com o auxílio de profissionais Médicos Veterinários ou técnicos. Dentre as demais, em cinquenta e duas propriedades foi afirmado contar com serviços de assistência técnica, sendo que quarenta e quatro eram de origem particular. Cinco propriedades recebiam assistência técnica fornecida pelos laticínios que coletavam o leite, duas propriedades eram visitadas pelo Médico Veterinário oferecido pela Prefeitura Municipal e uma pelo profissional disponibilizado pela cooperativa de leite.

Entretanto, segundo declarações dos próprios produtores, a maioria das visitas de assistência técnica não era feita de forma periódica. Apenas dois produtores declararam que recebiam visitas com frequência, um semanalmente e outro a cada dois meses.

Todas as propriedades visitadas afirmavam vacinar os animais como medida preventiva. Setenta e cinco por cento vacinavam para carbúnculo, sete por cento para leptospirose, seis por cento para IBR, três por cento para tétano, vinte e sete por cento para raiva, noventa e sete por cento para febre aftosa e noventa e três por cento para brucelose.
Quanto a vermifugação dos animais, cinquenta e três produtores declararam não adotar um calendário de vermifugação. Por outro lado, verificouse que o uso de substâncias para o controle de ectoparasitas ocorria em cem por cento das propriedades. Constatou-se que em setenta e oito por cento das propriedades o controle foi feito apenas quando considerado necessário, ou seja, quando ocorreu infestação do agente. Em sete propriedades 0 controle era feito diariamente, através da utilização de medicamentos homeopáticos introduzidos na alimentação dos animais, em outras cinco propriedades o controle aconteceu nos meses de verão, quando havia maior incidência, em quatro propriedades 0 controle era realizado todo mês e em outras duas, a cada três meses. Em uma propriedade o tratamento era feito a cada vinte dias e em outra a cada seis meses.

Com relação a origem da água oferecida aos animais, constatou-se que em oitenta por cento das propriedades não existia nenhum tipo de monitoramento da qualidade microbiológica da água, sendo esta proveniente de diferentes locais, como poço $(64 \%)$, sanga (33\%) e rio $(8 \%)$.

Quanto aos cuidados de biossegurança relacionados ao parto dos animais, apenas em vinte e oito por cento das propriedades as pessoas envolvidas com o manuseio dos animais declararam utilizar luvas por ocasião do parto, sendo que em sessenta e sete por cento das propriedades os produtores apenas lavavam as mãos como forma de prevenção. Quanto às medidas de prevenção a infecção do rebanho associadas ao parto dos animais, a maioria das propriedades, oitenta e dois por cento, não dispunha de local exclusivo para o parto das fêmeas.

Em relação a saúde e crescimento dos bezerros, em oitenta e 
um por cento das propriedades os produtores declararam que ocorria a ingestão do colostro nas primeiras horas após o nascimento. Entretanto, setenta e seis por cento dos entrevistados declararam não realizar 0 armazenamento do colostro. A maioria, sessenta por cento, utilizava bezerreiro coletivo, e vinte por cento, casinha. Porém na alimentação de indivíduos desta faixa etária trinta e seis por cento utilizava leite proveniente de vacas com mastite, e sessenta e um por cento fornecia leite de vacas que estavam sendo tratadas com antibióticos.

Quanto à utilização de medicamentos de uso veterinário para o controle e prevenção de doenças do rebanho, em noventa e sete por cento das propriedades os produtores afirmaram que observavam a data de validade dos medicamentos administrados, e em oitenta e três por cento das propriedades foi confirmado que o conteúdo dos frascos é conferido e analisado antes da aplicação, para garantir a qualidade e também a eficácia do produto.

Em contrapartida, os materiais perfuro-cortante como agulhas e seringas não receberam o tratamento correto quando descartados pela maioria dos produtores (Tabela 2).

\begin{tabular}{lcc}
$\begin{array}{l}\text { Tabela } 2 \text { - Destino dos materiais perfuro-cortante e das carcaças de } \\
\text { animais mortos nas propriedades visitadas. }\end{array}$ \\
$\begin{array}{l}\text { Destino do material } \\
\text { perfu ro co rtante }\end{array}$ & $\mathbf{N}^{\circ}$ de Propriedades & $\%$ \\
\hline Enterrado & 24 & 24 \\
Lixo comum & 27 & 27 \\
Reutilizado & 30 & 30 \\
Reciclado & 11 & 11 \\
Queimado & 8 & 8 \\
Total & 100 & 100 \\
\hline Destino das carcaças & $\mathbf{N}^{\circ}$ de Propriedades & $\%$ \\
\hline Enterrado & 62 & 62 \\
Queimado & 5 & 5 \\
Deixado ao ar livre & 28 & 28 \\
Enterrado e/ ou deixado ao ar livre & 2 & 2 \\
Enterrado e/ ou queimado & 1 & 1 \\
Não houve casos & 2 & 2 \\
Total & 100 & 100 \\
\hline
\end{tabular}

No caso de animais doentes, sessenta e sete por cento das propriedades não faziam o isolamento destes animais. Além disso, em vinte e oito por cento das propriedades não era dado o destino sanitário às carcaças de animais mortos, ficando as mesmas ao ar livre (Tabela 2).

Quanto ao controle de pragas, oitenta e nove por cento dos produtores declararam combater roedores como medida higiênico-sanitária, setenta e seis por cento declararam realizar 0 controle para moscas e vinte e quatro por cento alegaram não terem problemas com este tipo de praga na propriedade.

\section{DISCUSSÃO}

O processo de desenvolvimento da produção de leite é recente no Sudoeste do Paraná, região onde está localizado o Município de Realeza. Este sistema iniciou-se há menos de duas décadas, a partir da ação conjunta do poder público, movimentos sociais, cooperativas da agricultura familiar e instituições de extensão e assistência técnica rural. Naquele momento, ocorreram a abertura de linhas de financiamentos específicas para a agricultura familiar, e a instalação de um mercado de venda de animais, equipamentos de ordenha e insumos para a produção. Também foram tomadas iniciativas para qualificar os produtores. Laticínios, sindicatos e órgãos ligados a Federação da Agricultura do Estado do Paraná promoveram cursos de qualificação para os produtores que iniciavam na produção leiteira (Telles et al., 2008).

Este esforço resultou em um expressivo aumento da produção leiteira regional. Em 1990 a produção era de 147.338 litros, passando para 956.341 litros em 2010 (Mezzadri, 2012). Ou seja, um aumento de $549 \%$ em 20 anos. Contudo, este expressivo sucesso 
quantitativo não foi acompanhado pela produção de leite com boa qualidade microbiológica. Segundo dados do IAPAR do ano de 2011, mais de $67 \%$ dos agricultores familiares da região estavam produzindo leite fora dos padrões de contagem bacteriana total e de células somáticas preconizados pela Instrução Normativa № 51, ainda vigente naquele ano (Hill et al., 2011).

$\mathrm{Na}$ origem deste problema estão aspectos ligados à sanidade do rebanho leiteiro, e ao desconhecimento dos produtores sobre os mesmos, o que foi constatado por este trabalho. Conhecimentos básicos de cuidados com a sanidade do rebanho, como os riscos envolvidos na introdução de animais, ainda são negligenciados. Um dos fatores que levam a introdução de doenças em rebanhos leiteiros é o trânsito e a reposição de animais (Santos, 2003). Neste item, trinta e seis por cento dos produtores declararam adquirir animais externos para reposição, sendo que mais da metade destes o fazia sem a realização de exames. Este é um dado preocupante, se for considerado em conjunto com a ausência de controle de trânsito de animais, e a não realização da quarentena. Isto sem falar que, na região, algumas propriedades realizam a monta natural como método de reprodução de rebanho, acrescida pela prática de empréstimo de touro entre vizinhos. Sabe-se que a utilização de touros na monta natural é um grande fator de risco para a transmissão de doenças como campilobacteriose, tricomonose bovina, diarréia viral bovina e herpervírus bovino (Thomas, 1999). Assim, esta situação configura um risco sanitário, tanto por propiciar a ocorrência de doenças por introduzir animais susceptíveis em rebanhos estabilizados para uma determinada enfermidade, quanto pela introdução de animais doentes em rebanhos susceptíveis (Santos, 2003).
$\mathrm{Na}$ população estudada, 0 monitoramento da saúde do rebanho, através da realização de exames laboratoriais, pode ser considerado insatisfatório, pois quarenta e sete por cento dos produtores responderam que - faziam, e apenas vinte e sete por cento realizavam esta prática com periodicidade. Mesmo para os exames de brucelose e tuberculose, apenas oito por cento declarou a realização anual.

Os exames microbiológicos para amostras de leite em casos de mastite só foram declarados em 3 por cento das propriedades, o que torna improvável o diagnóstico etiológico das mastites subclínicas, a instituição da terapia da vaca seca, e principalmente, o uso racional de antibióticos sem o risco da ocorrência de resistência.

A ausência das informações sobre a saúde dos animais a partir de exames também dificulta 0 planejamento de outras medidas de prevenção e controle de doenças. Em especial a vacinação. Embora todas as propriedades visitadas tenham afirmado vacinar os animais como medida preventiva, não houve adoção de um planejamento com relação aos períodos de vacinação ao longo de ano, com exceção obviamente daqueles que são estabelecidos pelos órgãos oficiais. Problema semelhante ocorreu também com o combate a parasitas. Apesar de todos os produtores declararem a realização de controle de ectoparasitas, e praticamente a metade da população pesquisada afirmar que vermifugava os animais, isto não foi realizado de forma planejada através da elaboração de um calendário. Estas dificuldades indicaram que não havia elaboração de estratégias preventivas objetivando otimizar recursos humanos, físicos e econômicos. Nesta perspectiva, a elaboração de um calendário vacinal e de controle parasitário, considerando os aspectos epidemiológicos da região, 
seria a medida preventiva correta a seguir.

A percepção dos riscos ambientais à saúde dos animais também pode ser considerada como baixa. Apesar da maioria dos produtores ter afirmado que faziam o controle de praga, especialmente roedores e moscas, apenas 20 por cento declararam monitorar a qualidade da água. Um risco não apenas para a saúde dos animais, e dos produtores, mas também uma fonte de contaminação para o leite produzido. Corroboram para isto a ausência de cuidados com 0 destino de materiais perfuro-cortantes e de carcaças de animais mortos e a realização de partos e manuseio de fetos abortados sem 0 uso de luvas, e a não realização de isolamento de animais doentes do resto do rebanho. O risco de contagio de seres humanos e animais por brucelose deve ser considerado, principalmente quando animais acometidos por brucelose eliminam 0 agente no ambiente durante 0 aborto e parto (Lage et al., 2008). Além disso, existe o fato de não isolar os animais doentes, 0 que predispõe a ocorrência de surtos.

$$
\text { Entre outros aspectos }
$$

observados quanto aos cuidados com a sanidade do rebanho, pode-se dizer que a maioria dos produtores fazem uso de fármacos para o controle e prevenção de doenças do rebanho, tendo cuidados para garantir a qualidade e a eficácia do produto. Também ocorre o fornecimento de colostro aos bezerros nas primeiras horas de vida, mas em muitas propriedades não existe o armazenamento do colostro. Sendo que alguns bezerros recebem leite proveniente de vacas com mastite, ou que estão sendo tratadas com antibióticos. Sabe-se que o leite com resíduo de antibióticos apresenta baixa palatabilidade, alta taxa de rejeição, leva a diminuição na taxa de crescimento de bezerros e também pode causar resistência bacteriana (Wray et al., 1990).

Os fatores que levam a esta situação podem ser relacionados ao baixo grau de escolaridade dos produtores. Segundo dados do censo agropecuário de 2006, o percentual de agricultores que não sabem ler e escrever era de quarenta e um por cento (IBGE, 2012). Já em 2012, um estudo realizado pelo Ministério da Agricultura, Pecuária e Abastecimento, sobre o diagnóstico da pecuária leiteira nacional, revelou que cinquenta e sete por cento dos produtores agrícolas do Brasil são analfabetos (MAPA, 2012). Porém, a produção de leite por agricultores familiares no sudoeste paranaense está associada ao aumento do grau de escolaridade, (Kyota et al., 2012). Além disto, em uma comparação realizada entre produtores com diferentes níveis de produtividade no sudoeste paranaense, não foram verificadas diferenças provocadas pelo grau de escolaridade dos mesmos (Parré, 2011).

Entretanto, há necessidade de se considerar a ausência de assistência técnica como fator determinante na não adoção de medidas de prevenção com relação a saúde do rebanho. Neste trabalho verificou-se a quase completa ausência de uma assistência técnica médica veterinária regular aos produtores. Mesmo para os quarenta e oito por cento que afirmaram possuir assistência técnica, a ausência de periodicidade não configurava a presença do serviço de forma efetiva, apenas um produtor declarou possuir assistência técnica regular. Os motivos desta ausência muito provavelmente estão ligados ao custo, em especial quando se considera a escala de produção média por propriedade na região 


\section{CONCLUSÃO}

Grande parte dos produtores de leite da agricultura familiar do município de Realeza-PR desconhece a maioria das práticas de biossegurança que devem ser aplicada ao rebanho leiteiro. Assim, com um manejo sanitário realizado de forma incorreta, existe o perigo de disseminação de doenças entre os animais, o que poderá causar prejuízos econômicos provocados pela diminuição da produção, morte de animais e descarte do leite. Além disso, o manejo inadequado de animais doentes representa um risco à saúde pública, tanto para as pessoas que trabalham diretamente com o rebanho, quanto para as que consomem o leite produzido.

\section{NOTAS INFORMATIVAS}

A pesquisa desenvolvida foi previamente aprovada pelo Comitê de Ética em Pesquisa da Universidade Estadual do Oeste do Paraná (UNIOESTE), sob o parecer no 338/2011-CEP.

\section{REFERÊNCIAS}

BRASIL. Ministério da Agricultura, Pecuária e Abastecimento. Instrução Normativa № 62. Brasília, DF, MAPA, 2011. 24 p. Disponível em: <http://www.hidrolabor.com.br/IN62.pdf>; Acesso em: 09 mai. 2012.

CASARI, P.; TORMEM, P. Atividade leiteira, agricultura familiar e desenvolvimento regional: estudo de caso da Linha Tormem, Chapecó - SC. 2007. Disponível em:

http://online.unisc.br/seer/index.php/cepe/article/ viewFile/936/1687. Acesso em: 21 abr 2012.

HILL, J.A.G.; SILVEIRA, A.L.F.; MIGLIORINI, F. et al. Qualidade do leite na região sudoeste do Paraná. IAPAR, Londrina, 2011. Boletim Técnico no $76.56 p$.

HOOGERHEIDE, S. L.; MATTIODA, F. Qualidade bacteriológica do leite cru refrigerado em propriedades rurais do estado do Paraná.
Revista do Instituto de Laticínios Cândido Tostes, v.67, n.385, 2012.

IBGE. Instituto Brasileiro de Geografia e Estatística. CENSO AGROPECUÁRIO 2006. Rio de Janeiro: IBGE, 2012. 774p. Disponível em:

<http://biblioteca.ibge.gov.br/visualizacao/periodi cos/51/agro_2006.pdf>. Acesso em: 04 mai 2013.

IPARDES. Caracterização socioeconômica da atividade leiteira no Paraná: sumário executivo. IPARDES, Curitiba, 2009. Disponível em:

<http://www.ipardes.gov.br/biblioteca/docs/suma rio_executivo_atividade_leiteira_parana.pdf $>$. Acesso em: 21 abr $201 \overline{2}$.

KIYOTA, N.; PERONDI, M.A.; SIMONETTI, D. et al. A produção familiar de leite no território sudoeste do Paraná nos anos agríclolas de 2004/05 e 2009/10: o caso do município de Itapejara d'Oeste. In: IX Congresso da Sociedade Brasileira de Sistemas de Produção (IX CSBSP) - Ciência, Tecnologia e Inovação para o Desenvolvimento Rural Sustentável. Brasíllia, 2012. Disponível em:

<http://www.iapar.br/arquivos/File/zip_pdf/redere ferencia/artigoGD1_32_NormaKiyota.pdf>. Acesso em: 04 mai $20 \overline{13}$.

LAGE, A. P.; POESTER, F. P.; PAIXÃO, T. A. Brucelose bovina: uma atualização. Revista Brasileira de Reprodução Animal, v.32, n.3, p.202-212, 2008.

MAPA. Ministério da Agricultura, Pecuária e Abastecimento. PLANO PECUÁRIO

NACIONAL 2012/2013 - Proposta preliminar da Embrapa Gado de Leite. 2012. Disponível em :

<http://www.agricultura.gov.br/arq_editor/file/ca maras_setoriais/Leite_e_derivados/30RO/App_P PN_Leite.pdf>. Acesso em: 04 mai 2013.

MATTIODA, F.; BITTENCOURT, J. V. M.; KOVALESKI, J. L. Qualidade do leite de pequenas propriedades rurais de Fernandes Pinheiro e Teixeira Soares - PR. Revista ADMpg Gestão Estratégica, v.4, n.1, p.1-9, 2011.

MEZZADRI, F.P. Análise da Conjuntura Agropecuária ano 2011/12 - LEITE. Estado do Paraná - Secretaria da Agricultura e do Abastecimento - Departamento de Economia Rural. 2012. 33p. Disponível em:

<http://www.agricultura.pr.gov.br/arquivos/File/d 
eral/Prognosticos/leite_2012.pdf>. Acesso em: 21 abr 2013.

NERO, L. A.; MATTOS, M. R.; BELOLI, V. et al. Leite cru de quatro regiões leiteiras brasileiras: perspectivas de atendimento dos requisitos microbiológicos estabelecidos pela Instrução Normativa 51. Ciência e Tecnologia de Alimentos, v.25, n.1, p.191-195, 2005.

NUNES, S. P. Censo Agropecuário demonstra aumento das escalas de produção e redução das ocupações agrícolas. DESER, 2008. 17p. Boletim Eletrônico, 164. Disponível em:

<http://www.deser.org.br/boletins/AnaliseCenso Agro.pdf>. Acesso em: 07 jul. 2012.

OLIVEIRA, L. R. S; ALVES, K. S.; GOMES, D. I. et al. Qualidade físico-química do leite fluido comercializado no sudeste paraense. Revista de Ciências Agrárias, v.55, n.1, p.61-65, 2012.

PARRÉ, J.L.; BÁNKUTI, S.M.S.; ZANMARIA, N.A. Perfil soioeconômico de produtores de leite da região sudoeste do Paraná: um estudo a partir de diferentes níveis de produtividade.

Revista de Economia e Agronegócio, v.9, n.2, 2011.

SANTOS, M. V. Biossegurança aplicada ao controle de mastite. Balde Branco, v.463, p.6265, 2003.

THOMAS, D. Venereal Diseases in the Bull. Bullish on Quality Beef, p.71-76, 1999.

Disponível em:

<http://www.animal.ufl.edu/extension/beef/shortc ourse/1999/OVERBAY.pdf>. Acesso em: 04 mai 2013.

TELLES, T.S.; TANAKA, J.M.U.; PELLINI,T. Agricultura familiar: pecuária leiteira como locus das políticas públicas paranaenses. Semina: Ciências Agrárias, Londrina, v.29, n.3, p.579590, 2008.

WRAY, C.; FURNISS, S.; BENHAM, C. L. Feeding antibiotic-contaminated waste milk to calves--effects on physical performance and antibiotic sensitivity of gut flora. British

Veterinary Journal, v.146, n.1, p.80-7, 1990. 